\title{
Wisata Dolanan: Pengembangan Wisata Tematik Berbasis Budaya di Kampung Biru Arema (KBA) Kota Malang
}

\section{Traditional Games Tourism: Culture-Based Thematic Tourism Development in Kampung Biru Arema (KBA) Malang City}

\author{
Hamamah $^{1}$, Agus Suman ${ }^{2}$, Fredy Nugroho Setiawan ${ }^{3}$, Rizki Nufiarni ${ }^{4}$ \\ Universitas Brawijaya, Malang, Indonesia \\ 1hamamah@ub.ac.id, ${ }^{2}$ agusuman@ub.ac.id, ${ }^{3}$ fredyns@ub.ac.id,
}

Riwayat Artikel: Dikirim 15 November 2020; Diterima 22 November 2020; Diterbitkan 30 November 2020

\begin{abstract}
Abstrak
Artikel ini memaparkan tentang upaya pengembangan salah satu area wisata yang ada di Kampung Biru Arema $(\mathrm{KBA})$, yaitu Area Dolanan. Area Dolanan merupakan salah satu dari lima area wisata yang ada di KBA yang dikembangkan secara kolaboratif antara tim dari Fakultas Ilmu Budaya Universitas Brawijaya dan masyarakat KBA. Pengembangan Area Dolanan berbasis kearifan lokal, yaitu dengan memunculkan ragam permainan tradisional berupa tapak gunung (engklek), congklak (dakon), dan gasing dengan desain yang modern sehingga dapat berterima, terutama bagi wisatawan dari kalangan anak muda. Area Dolanan diharapkan dapat menjadi identitas khas KBA sekaligus dapat menjadi wahana wisata edukatif yang mengenalkan kekayaan budaya lokal dalam kemasan community-based tourism.
\end{abstract}

Kata kunci: KBA; Area Wisata Dolanan

\begin{abstract}
This article describes efforts to develop one of the tourism areas in Kampung Biru Arema (KBA), namely the "Dolanan" (Traditional Games) Area. The "Dolanan" Area is one of the five tourism areas in KBA which is being developed collaboratively between a team from the Faculty of Cultural Studies Universitas Brawijaya and local community. The development of the area is based on local wisdomby introducing a variety of traditional games, namely: "tapak gunung (engklek.)", "congklak (dakon)", and "gasing" (spinning tops)presented with modern designs so that they are acceptable, especially for the young generation. The "Dolanan" Area is expected to become a distinctive KBA identity as well as a medium for educational tourism that introduces the richness of local culture in the packaging of community-based tourism.
\end{abstract}

Keywords: KBA; The "Dolanan" Tourism Area

\section{PENDAHULUAN}

Berwisata adalah salah satu kebutuhan wajib untuk masyarakat masa kini. Berwisata kini menjadi kebutuhan primer yang setara dengan kebutuhan sandang, pangan, dan papan (Hariyanto, Andriana, \& Kristiutami, 2018). Hal ini juga diikuti dengan meningkatnya tingkat stres, karena pekerjaan yang diampu sehari-hari, sehingga saat akhir pekan datang, orang berbondongbondong pergi ke tempat wisata untuk mendapatkan udara segar. Selain itu, membaiknya perekonomian masyarakat mendorong masyarakat untuk berwisata dan juga mendorong para investor untuk membuka wahana wisata baru (Haryati \& Hidayat, 2019).

Terkait dengan kebutuhan akan wahana wisata baru, Pemerintah Kota Malang menggalakkan wisata berkonsep kampung tematik untuk menawarkan opsi wahana wisata baru yang tidak hanya dapat menarik wisatawan tetapi juga dapat meningkatkan perekonomian warga di wilayah perkampungan yang dulunya kumuh. Hal tersebut sesuai dengan prinsip 
pengembangan pariwisata yang tidak hanya bertujuan meningkatkan perekonomian masyarakat, tetapi juga meningkatkan pendapatan daerah dan negara (Haryati \& Hidayat, 2019).Salah satu kampung wisata tematik yang digagas oleh Pemerintah Kota Malang adalah Kampung Biru Arema (KBA) yang terletak di kelurahan Kiduldalem. KBA merupakan kampung wisata yang diresmikan oleh pemerintah kota Malang bekerja sama dengan sponsor perusahaan cat, PT Indana Paint. Kolaborasi tersebut menghasilkan bangunan-bangunan rumah warga yang berwarna biru. Bentuk pengembangan seperti ini sangat strategis untuk pemberdayaan masyarakat yang tinggal di wilayah tersebut (Saepudin, Budiono, \& Halimah, 2019).

Meskipun upaya pendirian sebuah kampung wisata tematik telah dilakukan, pengembangan dan pengelolaan potensi wisata KBA belum memberikan dampak positif yang maksimal bagi masyarakat KBA. Pernyataan tersebut dibuat berdasarkan perolehan keuntungan finansial warga dari kampung wisata KBA, yang didapatkan dari biaya parkir dan tiket masuk, yang minim dan kalah bersaing dengan Kampung Warna-Warni dan Kampung Tridi yang berada di sebelahnya. Selain itu, ketiadaan rencana pengembangan yang terstruktur dan rendahnya motivasi warga untuk mengembangkan potensi kampung mereka juga menjadi tantangan untuk memaksimalkan potensi wisata KBA. Oleh karena itu, untuk meningkatkan gerak roda perekonomian masyarakat KBA, Tim Pengabdian kepada Masyarakat Fakultas Ilmu Budaya (FIB) Universitas Brawijaya (UB) melakukan pendampingan di tahun 2019 untuk menaikkan potensi kampung wisata KBA menjadi kampung wisata edukasi. Langkah inisiatif tersebut menghasilkan rute wisata dan 5 (lima) desain area wisata KBA. Langkah tersebut kemudian dilanjutkan oleh tim Doktor Mengabdi Universitas Brawijaya pada tahun
2020 dalam bentuk upaya membangun salah satu area wisata yang telah berhasil dipetakan, yaitu Area Dolanan.

Wisata edukasi adalah wisata yang menghadirkan hiburan yang terintegrasikan dengan pendidikan nonformal (Saepudin, Budiono, \& Halimah, 2019). Dengan demikian, wisatawan yang berkunjung ke area wisata tersebut tidak hanya mendapatkan hiburan, tetapi juga mendapatkan pengalaman belajar yang menyenangkan. Wisata seperti ini sedang digemari karena tidak hanya menyenangkan tetapi juga sebagai media yang efektif untuk meningkatkan atau mengelola perilaku sosial ketika berwisata, perkembangan kognitif, intelektual, emosi, dan juga secara fisik, dan juga efek terapeutik akibat meningkatnya level stres masyarakat modern (Rapeepisarn, Wong, Fung, \& Depickere, 2006).

Pengembangan kampung wisata tidak hanya sekadar bertujuan untuk menaikkan profit masyarakat daerah wisata dan memenuhi kepuasan wisatawan, namun juga untuk melestarikan nilai warisan budaya Indonesia. Hal ini sejalan dengan program Kementerian Pariwisata yaitu Pariwisata Berbasis Budaya dimana pengembangan wisata warisan budaya ini banyak diminati wisatawan global. Pariwisata Berbasis Budaya dikemas secara unik untuk memberikan pengalaman otentik tentang identitas budaya Indonesia. Dengan kata lain, daya tarik yang menjadi fokus pada pengembangan kampung wisata adalah produk budaya yang menyesuaikan tren dan permintaan pasar. Berdasarkan hal tersebut tim Doktor Mengabdi Universitas Brawijaya memberikan pendampingan kepada warga masyarakat KBA dalam upaya pembangunan dan pengembangan Area Dolanan KBA berbasis budaya. Konsep rancang bangun dan kemasan area tersebut diharapkan dapat memunculkan identitas KBA. Selain itu, dengan adanya area wisata yang terkonsep dan tersaji dengan baik diharapkan warga akan mendapatkan 
keuntungan secara material sehingga dapat menunjang perekonomian mereka.

\section{METODE}

Kegiatan tim Doktor Mengabdi Universitas Brawijaya di kampung wisata KBA difokuskan pada pendampingan pembangunan dan pengembangan potensi salah satu area wisata, yaitu Area Dolanan. Wisata dolanan ini dikemas menjadi salah satu ikon dari KBA yang mengusung tema edukasi. Langkah pengembangan Area Dolanan dilakukan dengan menerapkan prinsip community-based tourism yang dilakukan untuk memaksimalkan potensi wisata dan melibatkan warga masyarakat setempat untuk ikut andil dalam pembangunan pariwisata di KBA (Setiawan, Nufiarni, \& Pujiyanti, 2019). Tahapan yang dilakukan adalah:

a. Melakukan kajian pustaka terhadap studi dan hasil kegiatan terdahulu; yaitu mengacu pada kegiatan Pengabdian kepada Masyarakat yang dilakukan oleh tim Pengabdian kepada Masyarakat tahun 2019 dan memanfaatkannya sebagai titik tolak perencanaan kegiatan pengembangan Area Dolanan

b. Melakukan observasi lapangan dan wawancara tokoh Pokdarwis KBA; yaitu melakukan pemetaan dan pengukuran lokasi Area Dolanan dengan pendampingan konsultan dari Pokdarwis KBA agar dapat dibuat rancang bangun yang sesuai.

c. Menyusun rancang bangun; yaitu membuat desain arsitektur Area Dolanan berdasarkan pemetaan dan pengukuran yang telah dilakukan

d. Mengadakan Focus Group Discussion (FGD) dengan warga KBA untuk mendapatkan peran aktif warga dalam bentuk persetujuan dan masukan berupa gagasan baru, revisi rancang bangun, dan saran-saran lain terkait pembangunan Area Dolanan

e. Melakukan perbaikan rancang bangun berdasarkan FGD dengan warga KBA dan merancang rincian pembiayaan

f. Melaksanakan pembangunan Area Dolanan dengan melibatkan peran aktif warga KBA secara kekeluargaan dan gotong royong

\section{HASIL DAN PEMBAHASAN}

Area Dolanan telah dicetuskan tahun 2019 dan ditujukan sebagai suatu wahana permainan tradisional yang modern tanpa meninggalkan nilai-nilai budaya. Bertolak dari studi lapangan yang dilakukan oleh tim Pengabdian kepada Masyarakat Fakultas Ilmu Budaya Universitas Brawijaya (lihat: Setiawan, Nufiarni, \& Pujiyanti, 2019), tim Doktor Mengabdi Universitas Brawijaya memulai Langkah awal dengan membuat konsep awal terkait isi Area Dolanan. Area dolanan ini terbagi menjadi beberapa pembagian zona dan alur sirkulasi. Pembagian zona area dolanan adalah permainan congklak, permainan gasing, dan permainan tapak gunung. Terdapat zona pendukung di Area Dolanan, yaitu display informasi tentang permainan tradisional yang ditampilkan, alur permainan, sirkulasi, dan tempat duduk.

Identifikasi, pemetaan dan pengukuran lokasi Area Dolanan menggunakan metode observasi dan wawancara yang dilakukan dua kali. Kegiatan pertama dilakukan dengan melihat situasi lingkungan dan kondisi lapangan dimana Area Dolanan rencananya akan dibangun sehingga tim Doktor Mengabdi dapat memformulasikan langkah-langkah untuk membuat rancang bangun. Pada kegiatan kedua, tim melakukan observasi sekaligus wawancara di lokasi dengan konsultan, yaitu Pak Irmawan (Ketua Pokdarwis KBA), dan juga mendiskusikan rencana awal terkait rancang bangun sehingga mendapatkan masukan atau saran yang konstruktif. Berikut adalah gambar lokasi yang akan dibangun. 
Gambar 1.

Lokasi Pembangunan Area Dolanan

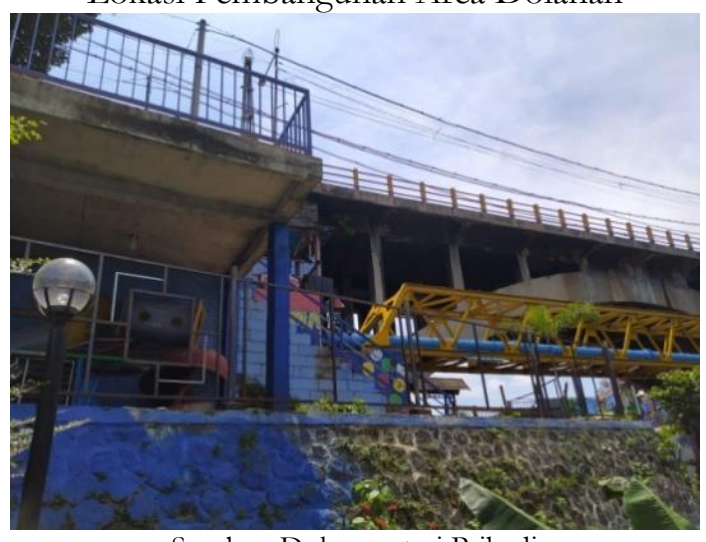

Sumber: Dokumentasi Pribadi

Setelah berhasil melakukan pemetaan dan pengukuran lapangan, tim Doktor Mengabdi menyusun sebuah rancang bangun Area Dolanan yang nantinya akan dibangun di lokasi yang telah ditentukan (Gambar 1). Dalam prosesnya, pembuatan rancang bangun tersebut melibatkan bantuan arsitek yang secara intensif berkoordinasi dengan tim Doktor Mengabdi dan ketua Pokdarwis. Hasilnya adalah kesepakatan awal mengenai desain Area Dolanan dengan memanfaatkan lahan terbatas di bawah jembatan "Buk Gludug" yang ikonik di wilayah kelurahan Kiduldalem. Lokasi tersebut dipilih berdasarkan 2 (dua) hal: pertama, lokasi tersebut berada sesuai dengan rute wisata KBA yang telah dirancang pada tahun 2019; kedua, lokasi tersebut merupakan lahan fasilitas umum yang paling luas yang belum dimanfaatkan secara maksimal oleh warga.

Setelah mencapai kesepakatan tentang lokasi pengembangan wisata Area Dolanan, tim Doktor Mengabdi melakukan diskusi lanjutan dalam bentuk Focus Group Discussion (FGD) dengan warga masyarakat KBA di balai RW terkait desain Area Dolanan di KBA. Dalam FGD tersebut tim Doktor Mengabdi mempresentasikan rencana rancang bangun dan warga menanggapi dengan memberikan umpan balik untuk perbaikan rancangan. FGD berhasil memfasilitasi peran aktif warga yang kemudian menyetujui usulan tim Doktor
Mengabdi dan memberikan catatan-catatan perbaikan.

Perbaikan rancang bangun dilakukan dengan melakukan observasi kembali ke lapangan bersama dengan arsitek dan pengurus Pokdarwis KBA untuk memastikan kesesuaian desain, keinginan warga, dan kesesuaian dengan lokasi yang telah ditentukan. Setelah dipastikan, desain akhir Area Dolanan dibuat dan dilanjutkan dengan penentuan timeline pelaksanaan pembangunan area tersebut yang disesuaikan program kerja yang akan dilaksanakan. Berikut adalah rancang bangun Area Dolanan yang telah disepakati

Gambar 2.

Rancang Bangun Area Dolanan KBA

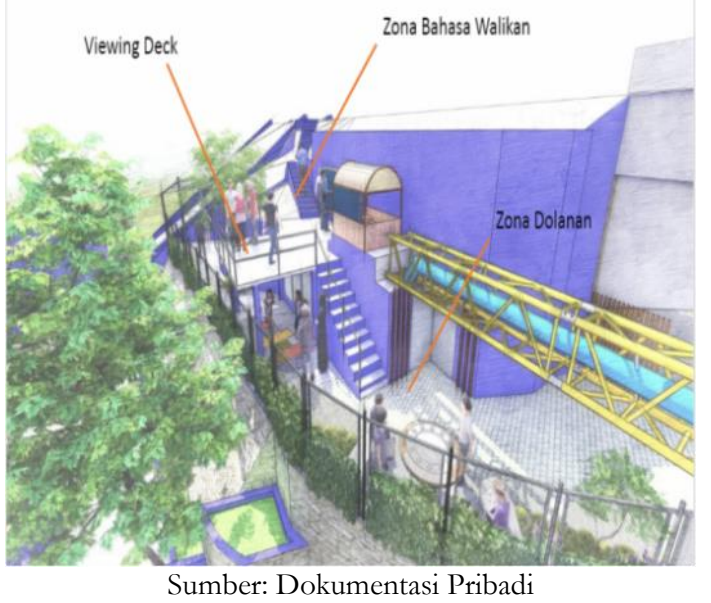

Pada tahap pelaksanaan, warga melakukan eksekusi kegiatan pembangunan dengan didampingi oleh tim Doktor Mengabdi yang melakukan fungsi supervisi implementasi rancang bangun. Di dalam Area Dolanan terdapat beberapa permainan tradisional, yaitu congklak, gasing, dan tapak gunung. Permainan tradisional dipilih karena merupakan salah satu bentuk warisan kebudayaan yang berguna sebagai sarana hiburan dan pendidikan tentang kearifan lokal. Dalam konteks kontemporer, permainan tradisional mulai jarang dikenal oleh generasi muda yang banyak terpapar oleh ragam permainan berbasis gawai dan digital. Dalam hal ini, mereka perlu untuk dikenalkan dengan beberapa permainan 
tradisional yang tidak hanya memiliki fungsi hiburan, tetapi juga mengandung nilai-nilai filosofis khas masyarakat setempat yang erat kaitannya dengan sikap dan kepribadian yang masih relevan hingga sekarang, misalnya mengajarkan kedisiplinan, kejujuran, kerja sama dan kebersamaan.

Pemunculan beberapa jenis permainan tradisional yang dulu pernah dikenal dan dilakukan oleh masyarakat setempat diharapkan dapat menghidupkan kembali romantisme tempo dulu sekaligus menjadi sarana edukatif, terutama bagi generasi muda, agar dapat mengenal, menghargai, dan bangga dengan kekayaan budaya dan kearifan lokal Malang. Area Dolanan juga diharapkan mampu menjadi salah satu identitas khas KBA sehingga dapat memenuhi ekspektasi wisatawan yang mencari opsi wahana wisata ikonik di kota Malang. Keberadaan Area Dolanan diharapkan dapat meningkatkan perekonomian warga sekaligus menjadi upaya konkret pelestarian salah satu warisan budaya Indonesia.

\section{KESIMPULAN}

Kegiatan yang dilaksanakan oleh Tim Doktor Mengabdi untuk mengembangkan Area Dolanan di KBA merupakan bentuk kolaborasi antara akademisi, praktisi, dan pelaku wisata yang terjalin dalam kerangka community-based tourism. Hasil kegiatan berupa rancang bangun pengembangan Area Dolanan dan proses pembangunan yang hingga saat tulisan ini dibuat masih berjalan, merupakan bukti bahwa pengembangan wisata tidak seharusnya hanya didominasi oleh kaum intelektual dan pemilik modal atau korporasi. Keterlibatan aktif pelaku wisata, yaitu warga masyarakat dimana lokasi wisata dikembangkan, merupakan hal yang harus dilakukan dalam upaya menciptakan keseimbangan antara kesejahteraan masyarakat sebagai subjek dan keuntungan finansial bagi daerah tempat wisata.

\section{DAFTAR PUSTAKA}

Agus, H., \& Sumaryadi. (2018). Pedoman Pengembangan Wisata Tematik Berbasis Budaya. Kementerian Pariwisata.

Hariyanto, O., Andriani, R., \& Kristiutami, Y. (2018). Pengembangan Kampung Tulip Sebagai Wisata Edukasi di Bandung". Jurnal Pengabdian Kepada Masyarakat, 1(1), 14-20.

Haryati, T., \& Hidayat, A. (2019). Konsep Wisata dari Perspektif Ekonomi Masyarakat. Jurnal Pendidikan IPS, 9(2), 113-122.

Rapeepisarn, K., Wong, K., Fung, C., \& Depickere, A. (2006). Similarities and Differences Between "Learn through Play" and "Edutainment". In Proceedings of the $3 r d$ Australasian Conference on Interactive Entertainment, 46 December 2006 (pp. 28-32). Perth:W.A.

Saepudin, E., Budiono, A., \& Halimah, M. (2019). Pengembangan Desa Wisata Pendidikan di Desa Cibodas, Kabupaten Bandung Barat. Jurnal Ilmu-Ilmu Sosial dan Humaniora, 21(1), $1-10$.

Setiawan, F.N., Nufiarni, Rizki, \& Pujiyanti, Fariska. 2019. "Pemetaan Rute Wisata Kampung Biru Arema (KBA) Kota Malang", dalam Jurnal Surya Masyarakat, Vol. 2 No. 1, November 2019, Hal. 35-44. 